\title{
Teachers' Professional Development on Media and Intercultural Education. Results from some participatory research in Europe
}

\author{
Maria Ranieri ${ }^{\mathrm{a}}$, Andrea Nardi ${ }^{\mathrm{b}}$, Francesco Fabbro ${ }^{\mathrm{c} 1}$ \\ ${ }^{a}$ University of Florence, Italy, maria.ranieri@unifi.it, http://orcid.org/0000-0002-8080-5436 \\ ${ }^{b}$ University of Florence, Italy, andrea.nardi@unifi.it \\ ${ }^{c}$ University of Florence, Italy, francesco.fabbro@unifi.it
}

\begin{abstract}
Media and intercultural education are being increasingly recognised as a fundamental competence for teachers of the 21st century. Digital literacy and civic competence are facing several new challenges in response to the intensification of migratory phenomena and the unprecedented spread of fake news, especially among adolescents at risk of social exclusion, but teachers' professional development is still far from coping with this emerging need. Intercultural understanding and a critical use of media among adolescents have now become primary goals for the promotion of active citizenship. This article intends to provide some recommendations on how to support teachers' professional development in the field of media and intercultural education. To this purpose, it presents and discusses the results of an action-research project aimed at teachers' improvement of teaching skills about the media in multicultural public schools. The results are part of a larger European project "Media Education for Equity and Tolerance" (MEET) (Erasmus Plus, KA3), an initiative promoted in 2016-2018 by the University of Florence (Italy).
\end{abstract}

Keywords: media literacy education, intercultural education, teacher training, secondary school, European programmes

\section{Introduction}

Over the last ten years, European instructional systems have witnessed a "competence turn" aimed at redefining the traditional framework of key competences to face the new challenges of the new century. In particular, in 2006, the European Parliament and Council issued a recommendation (EU Parliament and Council, 2006) through which the traditional numeracy and literacy-based paradigm was extended to eight competences, including digital competence, communication in foreign languages, social and civic competences and cultural awareness and expression. Roughly, digital competence means the capacity to understand ICT's risks and opportunities, while underlining its critical and reflective nature; communication in foreign languages involves the ability to use different languages appropriately and integrates a historical dimension and intercultural competences; civic competence refers to a knowledge of concepts such as democracy, justice, equality, citizenship and civil rights; lastly, cultural awareness and expression entails an open attitude and respect towards cultural diversities, not only looking at the European society but more generally at the global world. Pushing towards the adoption of new competences as a main objective for schools from now onwards has relevant consequences for education systems and their protagonists. First, it has an impact on the design of the curricula that should fit the emerging needs of our global digital societies and the related competences as highlighted in the new framework. Second, it implicates innovative programmes for teachers' professional development in order to prepare them to teach about these new areas and be able to guide their students in dealing with unprecedented risks and opportunities. Moving from principles to practice, how are European countries reacting to the new educational challenges? What are the most suitable approaches to teachers' professional development in these fields?

\footnotetext{
${ }^{1}$ This paper has been jointly conceived by the authors and its contents are the result of a common work of methodological and empirical investigation. Only for the purposes of this chapter, Maria Ranieri wrote sections 3.1, 6.1, 7; Andrea Nardi wrote sections 1, 3.2, 6.2, 8; Francesco Fabbro edited sections 2, 3.3,6.3. Sections 4 and 5 were jointly edited. Data providing the ground for the elaboration presented here are fully documented in the following national reports: Mayer (2018); Ranieri, Fabbro \& Nardi (2018); Šri \& Frelih (2018).
} 
The EC-funded project "Media Education for Equity and Tolerance" (MEET) (2016-2018) aimed at exploring these issues through the analysis of national policies on citizenship, media and intercultural education (CMIE) in five European countries (Austria, Belgium, Germany, Italy and Slovenia) and by engaging teachers in an action-research project to co-design and test learning scenarios on media and intercultural education. The project was promoted by the University of Florence (Italy) in collaboration with the University of Vienna (Austria), Peace Institute (Slovenia), Media Animation (Belgium) and medienbildung.com (Germany) through the involvement of 15 teachers and 141 students (aged 15-18 years) in six secondary schools located in Germany, Italy and Slovenia.

In the following sections, we first provide an overview of the CMIE policies in some European countries and then we illustrate and discuss the results of MEET action research in order to draw some recommendations for policy making.

\section{A snapshot of CMIE policies from five European countries}

CMIE have been highly debated in the last twenty years in Europe; sometimes, it has even been politically contested, especially citizenship and intercultural education (Opratko \& Sauer, 2019; Šori \& Pajnik, 2019). In the Austrian case, the implementation of CMIE in schools' curriculum has faced several barriers. CMIE are usually combined with other disciplines without finding a specific place in the curriculum. They are thought of in a fragmented way and very often are announced as a principle that does not translate into concrete practices. In addition, initiatives on teachers' training are not systematically implemented (Trültzsch-Wijnen, 2014).

In Belgium, a similar situation exists. For example, media literacy education is a transversal topic that is integrated in different parts of the curriculum, while its implementation relies on teachers' motivation and skills. The latter are not fully developed since teacher training on media literacy is limited, consisting of very short courses, often assimilated to educational technology programmes, leading to overlapping media education with the educational use of media. As for in-service teacher training, it is not compulsory and mainly based, again, on teachers' willingness to attend and the capacity of school networks and managers to organise specific programmes.

Moving to Germany, while political and civic education have been well established after the country's Nazi past, media education is not fully implemented in school curricula (Wetterich, Burghart \& Rave, 2014). On the contrary, NGOs and semi-state organisations are actively fostering media education, supporting the idea of integrating the topic either in school environments or in teacher training. Media education remains inadequately integrated in the curricula of the various school subjects.

In Italy, both media education and intercultural education have received increasing recognition in the last decade, although to different degrees. In fact, while media education has seen growing attention from the different stakeholders and has recently entered a national plan for the development of the digital school, intercultural education is still mainly perceived as an "emergency educational answer" addressing mostly migrant pupils in order to facilitate their integration. Indeed, media education has become an established field, especially thanks to the work of academicians who encouraged specialised studies on the topic and associations promoting media literacy between school and society. However, no systematic training is foreseen in the country either for future or in-service teachers (Ranieri \& Bruni, 2018) with negative implications for teachers' development of skills.

Finally, in Slovenia, after the transition to liberal democracy and market economy, citizenship education found its place in schools with a focus on "patriotic culture and ethics", neglecting diversity at schools or in the society (Bezjak \& Klemenčič, 2014). Intercultural education is meant as a cross-curricular topic that in principle should ensure more space for dealing with it, while in practice, this leads to a void relating to how this issue should be included in the school. Media education, instead, is not adequately addressed in the Slovenian school system.

In conclusion, all five countries considered here have encouraged the inclusion of CMIE in the school curricula in recent years. However, since CMIE are usually treated as cross-curricular topics, it really risks being overlooked with no systematic attention to its contents. Teacher education and training are mostly missing in all countries due to limited investment in terms of funding and time. Moreover, while citizenship education, media education and intercultural education are very close in terms of general purposes and educational approach, they are mostly dealt with separately. Thus, as observed by Opratko and Sauer (2019), "in the context of rising immigration cultural, religious but especially social diversity is not recognised in most of the curricula".

In an attempt to increase knowledge related to affordances and constraints for a better CMIE implementation at the school, this article focuses on the implications of MEET action research for teachers' professional development.

\section{MEET: a European project in secondary school}

\subsection{Context, aims and framework}

The MEET project aimed at promoting a critical and intercultural understanding as well as an aware use of media among young citizens in multicultural public schools and democratic societies by engaging students and teachers, in the secondary school, in an action-research process of co-designing and developing intercultural media education practices. The final goal of the project was to create innovative educational and training tools to support the upscale of the 
experimented practices through the provision of teaching materials and guidelines to the teachers. Specifically, at the end of the project MEET, a multimedia toolkit including various resources from theoretical and methodological guidelines to videos documenting educational practices was released to widen the adoption of MEET approach among teachers. To develop the toolkit, the partnership went through the following steps:

Phase 1. Needs' analysis and involvement. A review of policies on CMIE was carried out at the national level by each partner to identify policy areas needing improvements in terms of social inclusion of students at risk of social exclusion. In addition, contacts with local bodies such as municipalities and educational agencies were made to identify the schools to be involved in the action-research process (see also section 2.2).

Phase 2. Co-design and development. Based on good practices already tested in a previous European project (eEAV, 2012-14), the MEET research staff engaged with a process of co-design involving teachers to create learning scenarios on media and intercultural education. The co-design of learning scenarios was grounded on the Media and Intercultural Education Framework (MIEF) (Ranieri \& Fabbro, 2018), a paedagogical framework to identify learning objectives - defined in terms of skills and competences - at the intersection between media and intercultural education (Figure 1). This framework is conceived as a tool that teachers could utilise to better identify relevant competences in these fields. As is well known, media education is often confused with more instrumental approaches to the media shifting the focus from teaching or learning about the media to teaching or learning through the media. Similar dangers occur with intercultural education whereby it is overlapped with more exotic approaches to cultures (Ranieri \& Fabbro, 2019). Essentially, the competences highlighted in the framework come from the field of media education studies (Buckingham, 2013; Hobbs, 2010), which emphasised both critical understanding of media and media production and creativity, and from the reflection around the concept of intercultural competence (Perry \& Southwell, 2011). The latter has been defined as including both cognitive aspects such as knowledge of other cultures and affective components meaning positive attitudes towards other cultures, showing empathy, curiosity and respect (Hill, 2006).

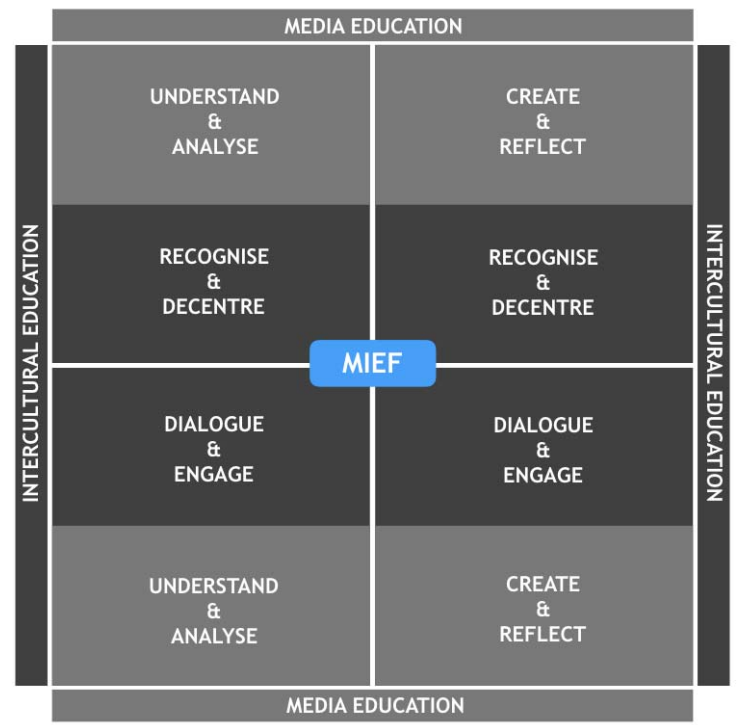

Figure 1. The Media and Intercultural Education Framework (MIEF)

Beyond the framework, MEET researchers also elaborated methodological guidelines to guide teachers in the design of media education practices for inclusive intercultural classes. The guidelines were inspired by the Universal Design for Learning (UDL) approach (Meyer, Rose \& Gordon, 2014), which have been reshaped according to a more contextualised approach based on sociocultural educational paedagogies (Vygotsky, 1978) while refocusing on media literacy education (Ranieri \& Fabbro, 2018). Concretely, the guidelines indicate specific paedagogical strategies to facilitate students' understanding, expression and engagement with (or without) the media within intercultural contexts. In particular, paedagogical strategies to scaffold students' understanding aim at identifying and mitigating potential obstacles to students' access and understanding of media (i.e. understanding of media representation, language, production and audiences) and topics such as tolerance, equity and social justice. Scaffolding students' expression concerns paedagogical strategies to reduce potential constraints to students' (media) voices and (self-) evaluation of learning. Finally, scaffolding students' engagement refers to paedagogical strategies to identify and minimise potential obstacles to students' commitment, particularly on an affective and social level. The adoption of MIEF and the guidelines led to the co-designing of six learning scenarios by the research teams from Germany, Italy and Slovenia.

Phase 3. Implementation and testing. The six learning scenarios were implemented in Germany, Italy and Slovenia over a period of about five months involving 141 students and 15 teachers. Students and teachers were involved in an action-research project, which led to the collection of several data about the process and its results. The data were analysed and coded to evaluate the learning experiences in terms of students' learning and teachers' reactions and improvement. 
Phase 4. Documentation and dissemination. All the implementation process was documented through the production of a "docutorial" (from documentary and tutorial). A docutorial has double objectives. On one hand, it aims at showing teachers how to teach media education in intercultural contexts (from this point of view, it is like a tutorial). On the other hand, it intends to document real educational situations through visual materials including teachers or researcher introducing concepts or moderating discussion as well as students interacting among them during debate or collaborative work in small groups. Together with the MEET conceptual background (i.e. MIEF) and the guidelines for teachers, the docutorial is part of the toolkit mentioned above that is now available online for sharing of good practice.

This article focuses on the results related to teachers' involvement in the action-research process, particularly in the second and third phases, in order to analyse teachers' reactions and improvement of teaching skills in media and intercultural education. In the following sections, we first introduce the training scenarios and describe teachers' characteristics and then the methods and the main results are presented.

\subsection{Training scenarios and participants}

Generally, MEET learning scenarios were made up of between 6 and 8 units lasting about 2 hours each. They included learning activities of both media analysis and production, and each unit was characterised by three teaching sequences, including Introduction, Activity and Conclusion, corresponding to the activation of students' pre-existing knowledge, engagement in exercises such as analysis of a media texts, role play, media writing, audio-production, and video production and final debriefing (see Table 1).

Table 1 - Paedagogical and media features of the learning scenario (LS)

\section{LS: Title/Authors/Abstract/Rationale/Participants/Keywords}

\begin{tabular}{|c|c|c|c|c|}
\hline $\begin{array}{l}\text { Number of the unit (U) } \\
\text { (between } 1 \text { and } 8 \text { ) and of } \\
\text { the teaching sequence } \\
\text { (TS) }\end{array}$ & $\begin{array}{l}\text { Learning objectives } \\
\text { according to MIEF }\end{array}$ & Paedagogical strategy & Evaluation strategy & $\begin{array}{l}\text { Media } \\
\text { focus }\end{array}$ \\
\hline U1/Un - Title & $\begin{array}{ll}- & \text { Understanding } \\
- & \text { Expression } \\
- & \text { Engagement }\end{array}$ & 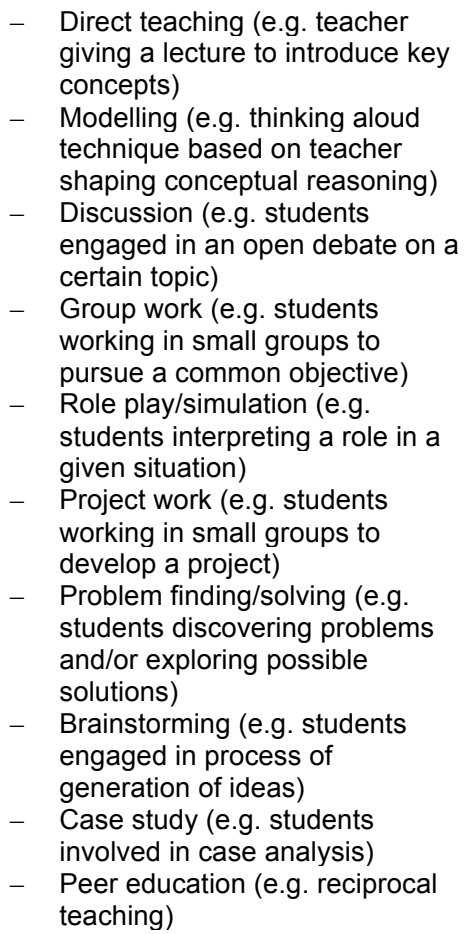 & $\begin{array}{l}\text { - Formative evaluation } \\
\text { (i.e. feedback provided } \\
\text { during the process) } \\
\text { - } \quad \text { Final evaluation (e.g. } \\
\text { using a rubric to } \\
\text { evaluate students' final } \\
\text { media products) } \\
-\quad \text { Self-evaluation (e.g. } \\
\text { students self-evaluate } \\
\text { their products) } \\
\text { Peer evaluation (e.g. } \\
\text { mutual evaluation } \\
\text { among studnts) }\end{array}$ & $\begin{array}{ll}- & \text { Video } \\
- & \text { News } \\
& \text { media } \\
- & \text { Poster } \\
- & \text { Social } \\
& \text { media } \\
- & \text { Radio } \\
& \text { podca } \\
& \text { st } \\
- & \text { Intern } \\
& \text { et } \\
- & \text { Other }\end{array}$ \\
\hline
\end{tabular}

A synopsis describing the main aims and contents of learning scenarios is reported in the following:

1) We are all equally different! aims at raising awareness among young people on how media represents reality and deals with radicalisation, as well as at guiding students' production of posters containing their slogans for an open and unbiased society.

2) In my own words is intended to raise students' awareness of propaganda and racism in politics and society and to promote their capacity to express their personal opinions on these issues through the creation of some video statements.

3) Challenge violence and play your rights (IT) aims at encouraging students to make sense of different uses and forms of violence at stake in video games and movies, as well as at scaffolding young citizens' ability to challenge violence - particularly violence against disadvantaged and marginalised individuals or social groups - in their own 
school community and more broadly in their everyday lives through the basic design of video games about human rights.

4) Questioning news media representations of “others" through video reporting aims at promoting students' critical understanding of news, particularly referring to fake news circulating through social media platforms around ethnic and cultural minorities, and promoting their capacity to express alternative narratives through video making and reporting.

5) Migration in Media Narratives and Digital Storytelling aims at providing students with critical frameworks and knowledge to understand the different media representations and life situations concerning the phenomenon of migration. Furthermore, it intends to teach how alternative media narratives about migration can be developed through the technique of digital storytelling.

6) Building a diverse and democratic community aims at providing students with skills and knowledge about living in a multicultural society and encourages their engagement for intercultural understanding, thereby specifically addressing diversity in the class, school and local community through the production of a radio podcast.

As already mentioned, the implementation of learning scenarios covered a period of 5 months, specifically from 9 November 2017 to 21 March 2018 with differences - in terms of time span - among the various educational interventions (EI) ranging between 8 days (EI 6) and 4 months (EI 5). Although different, the schools selected to participate in the action-research shared relevant features such as being a vocational or technical school located in socially disadvantaged urban areas and attended mainly by students with migrant backgrounds and/or low socioeconomic status (SES). As for the 15 teachers involved in the action-research project, who are the specific target of this article, their average age was 48 years and most of them had more than 10 years of teaching experience at school. In addition, most teachers were female and only 2 teachers had a migrant background. All participants had a bachelor's degree and 4 of them even a master. Furthermore, before the EIs, about two-thirds of the teachers already had some previous experience or training in media education and/or in intercultural education.

Tables 2 and 3 summarise the main characteristics of the EI and the background of our sample of teachers.

Table 2. Educational interventions (EIs) and their characteristics

\begin{tabular}{|c|c|c|c|c|c|c|}
\hline EI & Title & $\begin{array}{l}\text { Country and partner } \\
\text { (country) }\end{array}$ & City & No. of units/time & $\begin{array}{l}\text { Media } \\
\text { product }\end{array}$ & $\begin{array}{l}\text { No. of } \\
\text { students per } \\
\text { class }\end{array}$ \\
\hline EI 1 & We are all equally different & $\begin{array}{l}\text { Germany - } \\
\text { medienbildung.com }\end{array}$ & Ludwigshafen & 6 units $/ 12$ hours & Poster & 22 \\
\hline EI 2 & In my own words & $\begin{array}{l}\text { Germany - } \\
\text { medienbildung.com }\end{array}$ & Ludwigshafen & 6 units $/ 12$ hours & $\begin{array}{l}\text { Video } \\
\text { statement }\end{array}$ & 25 \\
\hline EI 3 & $\begin{array}{l}\text { Challenge violence and } \\
\text { play your rights }\end{array}$ & UNIFI (Italy) & Prato & 6 units $/ 12$ hours & $\begin{array}{l}\text { Videogame } \\
\text { design }\end{array}$ & 17 \\
\hline EI 4 & $\begin{array}{l}\text { Questioning news media } \\
\text { representations of "others" } \\
\text { through video reporting }\end{array}$ & UNIFI (Italy) & Prato & 7 units/18 hours & $\begin{array}{l}\text { Video } \\
\text { reportage }\end{array}$ & 27 \\
\hline EI 5 & $\begin{array}{l}\text { Building a diverse and } \\
\text { democratic community }\end{array}$ & MIROVNI (Slovenia) & Lendava & $\begin{array}{l}5 \text { units } / 7 \text { hours } 30 \\
\text { minutes }\end{array}$ & Radio podcast & 21 \\
\hline EI 6 & $\begin{array}{l}\text { Migration between media } \\
\text { narratives and digital } \\
\text { storytelling }\end{array}$ & MIROVNI (Slovenia) & Ljubljana & $\begin{array}{l}5 \text { Units } / 7 \text { hours } 30 \\
\text { minutes }\end{array}$ & $\begin{array}{l}\text { Digital } \\
\text { storytelling }\end{array}$ & 29 \\
\hline
\end{tabular}

Table 3. Teachers involved in the project and their characteristics

\begin{tabular}{|c|c|c|c|c|c|c|c|c|}
\hline $\begin{array}{l}\text { Educational } \\
\text { intervention } \\
\text { (EI) }\end{array}$ & $\mathbf{N}$ & Age & Gender & $\begin{array}{l}\text { Migrant } \\
\text { background }\end{array}$ & Education & $\begin{array}{l}\text { Previous } \\
\text { training in } \\
\text { media } \\
\text { education }\end{array}$ & $\begin{array}{l}\text { Previous } \\
\text { training in } \\
\text { intercultural } \\
\text { education }\end{array}$ & $\begin{array}{l}\text { Teaching } \\
\text { experience at } \\
\text { school }\end{array}$ \\
\hline El 1 & 2 & $\begin{array}{l}1 \rightarrow 43 \\
1 \rightarrow 38\end{array}$ & $\begin{array}{l}1 \rightarrow F \\
1 \rightarrow M\end{array}$ & $\begin{array}{l}1 \mathrm{st} \rightarrow 0 \\
2 \mathrm{nd} \rightarrow 0\end{array}$ & $2 \rightarrow$ Master & $2 \rightarrow$ Yes & $\begin{array}{l}1 \rightarrow \text { Yes } \\
1 \rightarrow \text { No }\end{array}$ & $\begin{array}{l}1 \rightarrow 10 \text { years } \\
1 \rightarrow 5- \\
10 \text { years }\end{array}$ \\
\hline El 2 & 2 & $\begin{array}{l}1 \rightarrow 59 \\
1 \rightarrow 61\end{array}$ & $2 \rightarrow \mathrm{F}$ & $\begin{array}{l}1 \mathrm{st} \rightarrow 0 \\
2 \mathrm{nd} \rightarrow 0\end{array}$ & $2 \rightarrow$ Master & $2 \rightarrow$ Yes & $2 \rightarrow$ Yes & $2 \rightarrow 10$ years \\
\hline EI 3 & 3 & $\begin{array}{l}1 \rightarrow 36 \\
1 \rightarrow 62 \\
1 \rightarrow 62\end{array}$ & $\begin{array}{l}1 \rightarrow F \\
2 \rightarrow M\end{array}$ & $\begin{array}{l}1 \mathrm{st} \rightarrow 0 \\
2 \mathrm{nd} \rightarrow 0\end{array}$ & $\begin{array}{l}3 \rightarrow \\
\text { Bachelor }\end{array}$ & $\begin{array}{l}1 \rightarrow \text { Yes } \\
2 \rightarrow \text { No }\end{array}$ & $3 \rightarrow$ Yes & $\begin{array}{l}2 \rightarrow 10 \text { years } \\
1 \rightarrow 5- \\
10 \text { years }\end{array}$ \\
\hline
\end{tabular}




\begin{tabular}{|c|c|c|c|c|c|c|c|c|}
\hline EI 4 & 4 & $\begin{array}{l}1 \rightarrow 49 \\
1 \rightarrow 41 \\
1 \rightarrow 31 \\
1 \rightarrow 39\end{array}$ & $\begin{array}{l}3 \rightarrow \mathrm{F} \\
1 \rightarrow \mathrm{M}\end{array}$ & $\begin{array}{l}1 \text { st } \rightarrow 0 \\
2 n d \rightarrow 0\end{array}$ & $\begin{array}{l}4 \rightarrow \\
\text { Bachelor }\end{array}$ & $\begin{array}{l}1 \rightarrow \text { Yes } \\
3 \rightarrow \text { No }\end{array}$ & $\begin{array}{l}2 \rightarrow \text { Yes } \\
2 \rightarrow \text { No }\end{array}$ & $\begin{array}{l}1 \rightarrow 10 \text { years } \\
2 \rightarrow 5- \\
10 \text { years } \\
1 \rightarrow 3- \\
5 \text { years }\end{array}$ \\
\hline EI 5 & 2 & $\begin{array}{l}1 \rightarrow 60 \\
1 \rightarrow 37\end{array}$ & $2 \rightarrow \mathrm{F}$ & $\begin{array}{l}1 \mathrm{st} \rightarrow 0 \\
2 \mathrm{nd} \rightarrow 0\end{array}$ & $\begin{array}{l}2 \rightarrow \\
\text { Bachelor }\end{array}$ & $\begin{array}{l}1 \rightarrow \text { Yes } \\
1 \rightarrow \text { No }\end{array}$ & $\begin{array}{l}1 \rightarrow \text { Yes } \\
1 \rightarrow \text { No }\end{array}$ & $2 \rightarrow 10$ years \\
\hline EI 6 & 2 & $\begin{array}{l}1 \rightarrow 47 \\
1 \rightarrow 59\end{array}$ & $\begin{array}{l}1 \rightarrow \mathrm{F} \\
1 \rightarrow \mathrm{M}\end{array}$ & $\begin{array}{l}1 \mathrm{st} \rightarrow 0 \\
2 \mathrm{nd} \rightarrow 0\end{array}$ & $\begin{array}{l}2 \rightarrow \\
\text { Bachelor }\end{array}$ & $2 \rightarrow$ Yes & $2 \rightarrow$ Yes & $2 \rightarrow 10$ years \\
\hline Total & 15 & $\begin{array}{l}48.26 \\
\text { (average) }\end{array}$ & $\begin{array}{l}7 \rightarrow \mathrm{F} \\
4 \rightarrow \mathrm{M}\end{array}$ & $\begin{array}{l}1 \text { st } \rightarrow 0 \\
2 \text { nd } \rightarrow 0\end{array}$ & $\begin{array}{l}11 \rightarrow \overrightarrow{ } \\
\text { Bachelor }\end{array}$ & $\begin{array}{l}5 \rightarrow \text { Yes } \\
6 \rightarrow \text { No }\end{array}$ & $\begin{array}{l}8 \rightarrow \text { Yes } \\
3 \rightarrow \text { No }\end{array}$ & $\begin{array}{l}7 \rightarrow 10 \text { years } \\
3 \rightarrow 5- \\
10 \text { years } \\
1 \rightarrow 3- \\
5 \text { years }\end{array}$ \\
\hline
\end{tabular}

\subsection{Teachers' engagement}

As far as the specific contribution of teachers in action research is concerned, they played different roles during the preparation of the learning scenarios, their implementation and the evaluation. Specifically, in the beginning, teachers were involved in the definition of the learning objectives of the learning scenarios: looking at MIEF, they decided which specific aspects to focus on according to the characteristics of the school or the needs of the students. For example, in EI 4, teachers proposed to work on fake news, social media and migration, since students were used to getting informed about local news through the Facebook Page of the town of Prato, which was dominated by fake news about migrant people living there. Teachers were also crucial in providing information about the students, their sociocultural backgrounds and linguistic skills, the climate of the class and the school, some pertinent and relevant events that occurred at the local level and so on. In a few words, they virtually meet students before meeting them physically. In addition, while the MEET research team was developing the educational materials, they provided some important feedback on the readability of the contents for a fragile audience as well as on sensitive aspects related to cultural differences.

During the implementation process, teachers first provided organisational support dealing with logistics, equipment, class schedule, and all aspects linked to the concrete development of the activity. They also encouraged, to different extents according to the specific context, sociorelational exchanges between students, students and teachers, students and researchers, especially at the beginning when everything was new. Along with the sociorelational support, in certain cases, they also played a paedagogical function accompanying the researchers/media educators in different ways such as raising questions for students' discussion and providing information to orient students and to encourage participation in collaborative works. At the end of the EI, teachers were asked to evaluate their experience through questionnaires and short interviews (see section 4).

\section{Research questions}

Three main research questions guided the evaluation of the impact of the action-research project on teachers' skills and involvement:

RQ1) How did teachers' involvement in the action-research project contribute (or not) to developing their media literacy skills?

RQ2) How did teachers' involvement in the action-research project contribute (or not) to developing their intercultural understanding skills?

RQ3) How did teachers' involvement in the action-research project contribute (or not) to developing their ability to teach media literacy education in intercultural contexts?

\section{Methods}

To answer the RQs in each country, researchers collected qualitative data through the following instruments:

1. A pre-survey that teachers answered before starting classroom activities. The survey included both closed and open questions such as "Have you had previous experience or training in Media Education?" or "How would you selfevaluate your ability to teach Media Literacy?".

2. A Logbook, specifically section 4 edited by MEET researchers, aimed at recording a global evaluation at the end of the EI.

3. A post-survey administered at the end of the EI. The survey included both closed and open questions such as "How would you self-evaluate your level of intercultural understanding?" or "Could you list and explain the strengths and weaknesses of the learning scenario in promoting students' media and intercultural competences?". 
Open answers in the questionnaires and the filed notes reported in the Logbooks were coded by each research team at the national level through a thematic analysis (Braun \& Clarke 2006). A "theory driven" (or deductive) approach was adopted since the identification of themes by each national team was based on a common analytical framework where the (sub-) dimensions of analysis were established a priori consistently with MIEF.

The findings were then analysed and (re)interpreted by the UNIFI team through a thematic synthesis (Kavanagh et al., 2012; Thomas \& Harden, 2008), which is essentially built on meta-ethnography (Noblit \& Hare 1988) and grounded theory (Strauss \& Corbin, 1998). The "raw data" in the MEET case were the texts from the national reports that were labelled by the authors as "findings" or "results". However, in our synthesis, similar to the meta-ethnographic approach, we elaborate the descriptive themes also by taking into account the "raw data" included in the primary reports (i.e. extracts from the Logbooks and open answers to questionnaires). While the thematic synthesis was mainly "theory driven", it included also new themes emerging from the comparison of the six thematic analyses. In this sense, it was also "data driven" (or "findings driven").

Drawing from Thomas \& Harden (2008), we carried out a thematic synthesis of qualitative findings about the impact on teachers in four steps: 1) Identifying the findings: findings of primary studies were identified taking into consideration participants' views about the impact of EI; then, they were entered verbatim into two different tables reporting students and educators' perspectives, respectively. 2) Coding findings: accounts from primary studies were coded highlighting the supporting (reciprocal translation) or dissenting (refutational translation) nature of the concepts identified. 3) Developing descriptive themes: through the comparison of descriptive codes aimed at finding similarities (i.e. evidence) and divergences (i.e. counterevidence), findings are organised into descriptive themes.

In this article, we focus on the results of the thematic synthesis that is basically qualitative in nature. Further quantitative information is available in Ranieri, Fabbro \& Nardi (2018).

\section{Results}

6.1 How did teachers' involvement in the action-research project contribute (or not) to developing their media literacy skills?

Mixed evidence was collected on teachers' media literacy skills. Specifically, in two cases (EI 3, 4), researchers observed that the level of improvement of teachers' media literacy skills varied according to two main factors, that is the duration of teachers' participation in the classroom activities and/or, of course, their pre-existing level of media literacy. For example, one researcher highlighted that the more teachers participated in the activity, the more they improved (EI 4), while another researcher underlined that the teachers' lack of familiarity with media analysis (EI 3) limited his/her contribution. In particular, concerning movie-trailer analysis, the researcher commented: "During the group work and the final discussion, teachers' contribution was relatively marginal. As the teachers themselves observed, neither the students nor the teachers were familiar with media analysis processes as proposed in the unit" (Logbook, Unit 2, EI 3, from Ranieri, Fabbro \& Nardi, 2018, p. 78). In a similar vein, one teacher in Ljubljana commented: "More experience with the pedagogical work, but not in the field" (Teachers' Post survey, EI 6, from Sori \& Frelih, 2018, p. 8).

This finding suggests how teachers' initial lack of knowledge about media analysis or a low exposure to classroom experience (e.g. just 1 or 2 lessons) can prevent them from developing a satisfactory level of media literacy skills, at least within the short time of MEET EIs.

Among the conditions preventing teachers' development of media literacy skills, the thematic synthesis of teachers and researchers' notes or comments pointed to two affordances of teachers' involvement in the action-research project. First, in some cases (e.g. EI 1, 4), teachers indicated the variety of teaching methods and the high quality of the educational materials - especially the videos - as two key strengths in the promotion of their own media literacy skills. Furthermore, one teacher stated that also direct observation of the implementation of such teaching strategies and materials provided them with an opportunity to develop new media literacy skills (EI 4). This positive contribution can be interpreted as a result of the situated and participatory nature characterising the design of classroom activities and/or, as one teacher suggested, the chance to observe directly the use of such teaching strategies and materials. One teacher in Ludwigshafen underlined that observing researchers or media educators implementing media education strategies worked as a form of modelling with positive implications for her motivation: "I got motivated to use media in teaching of different topics" (Teachers' Post survey, EI 2, from Mayer, 2018, p. 27).

Interestingly, in some cases (EI 3, 4), researchers reported how for some teachers the EI offered an opportunity to put into practice their pre-existing knowledge about media languages (i.e. audio-visual language and storytelling) in the context of media production (i.e. video reporting and videogame design). For example, as the following field note testifies, one teacher effectively supported students and researchers in the use of audiovisual tools: "Both teachers [] contributed to the development of the lesson: one teacher on the technical-organisational level, facilitating the use of the tools and enriching the presentation of the researcher with specific technical elements linked to the use of the audiovisual language" (Logbook, Unit 1, EI 4, from Ranieri, Fabbro \& Nardi 2018, p. 79). This comment reflects the understanding of the other teacher working in the same class who, while explaining her point of view on the experimentation, emphasised the role of her colleague: "One strength was the collaboration of the graphics teacher, 
who through her technical skills, was fundamental in the development of the final product" (Teachers' Post Survey, EI 4, from Ranieri, Fabbro \& Nardi 2018, p. 41).

In another situation (EI 3), instead, the researcher recognised the ability of one teacher to coordinate students' group work regarding the video game design, as well as her capacity to transfer her knowledge about classical storytelling techniques to video game design.

\subsection{How did teachers' involvement in the action-research project contribute (or not) to developing their intercultural understanding skills?}

A series of qualitative evidence was collected around teachers' understanding of the value of cultural plurality and democratic relations in the school context as well as their capacity to communicate and dialogue across a plurality of cultures. Through the analysis of researchers' accounts (i.e. field notes of the Logbooks) and teachers' open answers, some specific challenges emerged that teachers had to face with when addressing the migration issue in their classroom; this is the difficulty of mobilising students' genuine engagement in the discussion about the topic of migration.

For example, in one school (EI 3), a clear difficulty in fostering students' talk about migration was detected. In the following field note, the research observed how neither he nor the teacher was able to facilitate students' expression about the topic of migration: "In the final discussion on migration stories not even the teacher managed to encourage the students to express themselves on a topic that, as already highlighted above, had created a certain discomfort or disinterest among the students" (Logbook, Unit 1, EI 3, from Ranieri, Fabbro \& Nardi, 2018, p. 80).

Even another teacher in EI 4 highlighted a similar problem: "I can, however, say that the students were initially sceptical about the real usefulness of the Project but, thanks to the communication and technical skills of the two researchers/media educators, they felt appreciated and, for this reason, more motivated"' (Teachers' Post Survey, EI 4, from Ranieri \& Nardi, 2018, p. 41).

Of course, this difficulty should not be read exclusively as a matter of teacher's (and researcher's) lack of intercultural understanding skills. There are several factors, indeed, that may influence teacher and students' discussion around sensitive themes such as migration, including the social or the family perception of the phenomenon, how media represents migrants on the screen or the Internet and the pressure by peers to show aggressive behaviours. However, the situation suggests how a lack of familiarity with students' migrant backgrounds and/or their feelings about the migration issue may prevent educators from engaging students in genuine discussion about sensitive social topics.

In another case (EI 4), the researcher underlined the limits of the moralistic approach to migration-related issues adopted by some teachers, that is the narrowing of the conversation about migration to a "linguistic game" through which students must adhere with teachers' understanding of migration/migrants and, more broadly, with a pre-defined (and implicitly unquestionable) moral imperative. In this regard, the researcher observed: "On one hand, some teachers seemed to 'impose' a (politically correct) vision of migration and intercultural coexistence rather than negotiating it with the students. On the other hand, they seemed to embrace 'buoniste' narratives assuming migrants only as vulnerable people rather than individuals with rights" (Logbook, Unit 5, EI 4, from Ranieri, Fabbro \& Nardi 2018 , p. 80). Despite teachers' good intentions towards the promotion of democratic values when dealing with discussion about migration, the moralistic attitude proved to be counterproductive soliciting either students' conformist reactions based on the "social desirability" of the answer or oppositional responses seeing migrants as a threat for "our" societies or even only silence.

On the other hand, further qualitative findings shed light on the virtuous relations between teachers' involvement in the action-research project and their improvement of their intercultural awareness and their capacity to foster intercultural dialogue in the classroom (EI 4, 6). Again, according to some teachers, the concrete opportunity to learn from the active listening of the conversational exchanges between students and researchers or media educators, as well as from their own direct participation in the discussion, was pivotal in developing a greater ability to address sensitive issues such as ethnic prejudices and (anti-) racism (EI 4) and a renovated awareness of students' cultural diversity. As one teacher in Lendava stated, it "encourages understanding of what it means to be different" (Teachers' Post Survey, EI 5, from Šori \& Frelih, 2018, p. 16).

Teachers from two different schools explained that teaching activities provided opportunities to learn how to promote intercultural dialogue among students (EI 4) and develop intercultural awareness (EI 6). For example, in Slovenia, one teacher commented that MEET experience contributed to increasing his/her own intercultural awareness, which deals both with linguistic diversity and the everyday life experience of migrants and refugees. As regards the first aspect, the teacher observed: "The testing gave me an idea that I should pay attention to the understanding of Slovene language by a few students, coming from other countries, and that sometimes simplifying the words is not sufficient" (Logbook, Unit 1, EI 6, from Šori \& Frelih, 2018, p. 80). As far as the knowledge about the life situations of migrants and refugees in Slovenia, the teacher stated: "Even I was not aware about the documentation that foreigners must have if they want to live in Slovenia" (Logbook, Unit 4, EI 6, from Šori \& Frelih, 2018, p. 80). 
6.3. How did teachers' involvement in the action-research project contribute (or not) to developing their ability to teach media literacy education in intercultural contexts?

Overall, qualitative findings on teachers' ability to carry out media and intercultural education activities in the classroom indicate a general positive trend: in almost all cases (EI 2, EI 3, EI 4, EI 5, EI 6), teachers emphasised how the participation in the action-research project brought them to the discovery and acquisition of new paedagogical strategies and/or tools to teach in a more inclusive or intercultural way. One teacher in Germany (EI 2) underlined that the MEET experience encouraged to greater use of media for teaching purposes. Other teachers in Italy (EI 3, EI 4) and Slovenia (EI 5, EI 6) pointed out that the collaboration to the implementation of the activities led them to learn new approaches, methods or tools for designing or teaching about media within intercultural contexts, ranging from video reporting (EI 4) to the use of historical maps (EI 6) or digital storytelling (EI 6): "The map showing how migrations are universal features of humanity, and not only a modern phenomenon as it seems in the media lately, really impressed me: I will use it for sure in my future classes" (EI 6, Logbook, U4, from Šori \& Frelih, 2018, p. 82).

Interestingly, one teacher in Slovenia (EI 6) observed that teaching intercultural education meant going beyond simple recognition: "The method used in the beginning had a huge impact on me since I should be aware of the power of simple recognition. The culture of confirmation is indeed relevant in the teaching process and in everyday life" (EI 6 , Logbook, U3, from Šori \& Frelih, 2018, p. 82).

Furthermore, in almost all cases (EI 1, EI 2, EI 3, EI 4, EI 5), researchers underlined that teachers were able to support the teaching activities, contributing to stimulating the discussion (EI 1), guiding classroom activities and/or redesigning them (EI 3) and providing organisational (EI 4, EI 5) or technical support (EI 4). For example, in one case in Italy (EI 3), the teacher contributed to scaffolding students' media production activities, as the researcher reported: "Teachers encouraged students to interview people in the street looking at different ethnic groups. They also stimulated students to ask for relevant questions and have a role in the public sphere, see the interview with the Mayor of Prato or with the community (older people etc.)" (EI 4, Logbook 5, from Ranieri, Fabbro \& Nardi, 2018, p. 80).

In other cases (EI 2, EI 3), teachers provided a significant support to adapt the teaching materials to students' needs (EI 2), "The teacher suggested a change in regard to the Goebbels quote, and live research of billboards from the Nazi time and moderated it very efficiently" (Logbook 1, EI 2, from Mayer, 2018, p. 83), and to include disadvantaged students in the classroom activities (EI 3), "Marco's resistance to the activities, and the oppositional attitudes of the class against him, did not facilitate the climate even though it represented a reason for further reflection and a stimulus to continuously re-address the teaching modalities. This situation provided remarkable inputs to re-design teaching to meet cultures and promote the inclusion of diversity" (Teachers' Post Survey, EI 3, from Ranieri, Fabbro \& Nardi, 2018 , p. 83). This suggests that the action-research approach followed within MEET allowed teachers to effectively be engaged in the teaching process. At the same time, it indicates that there is potential in the school in terms of "human resources" to carry out such kinds of interventions.

However, there were also challenges to be taken into consideration. Specifically, some researchers (EI 4) highlighted that teachers were engaged at different levels and pointed out that they were less reactive in supporting the management of critical situations. From this point of view, the duration of the intervention was too limited: the development of more critical skills to teach about sensitive topics such as migration and social justice requires more time to get involved in delicate discussions in an appropriate way. Moreover, some teachers (EI 3) found that some educational objectives were unclear and that a certain fragmentation of learning scenarios was a constraint to effective teaching. Regarding the lack of time, one teacher in EI 3 observed: "During the work, especially during the production phase, some attitudes changed and moments of collaboration were created which, with more relaxed times, would have given rise to a more direct and aware involvement" (Teachers' Post Survey, EI 3, from Fabbro, 2018, p. 31), and one teacher underlined: "A few lessons to promote and consolidate the media and intercultural skills of students who have different learning styles and times are not enough" (Teachers' Post Survey, EI 4, from Ranieri \& Nardi, 2018, p. 40).

\section{Discussion}

The thematic analysis of qualitative findings from the national reports allowed us to identify some main constraints and affordances of the EI for teachers' development of skills in media and intercultural education. In this section, we highlight them to provide the ground for some recommendations to support future developments in the field.

Looking at constraints, it is evident how the relatively short duration of the intervention together with the low level of pre-existing media literacy skills had a negative influence on teachers' improvement of their skills. Indeed, since media literacy education does not have adequate space within the national curricula either as a specific discipline or as a transversal content (Parola \& Ranieri, 2010; Opratko \& Sauer, 2019; Šori \& Pajnik, 2019), the time devoted to MEET action research in each school was limited as limited were the teachers' skills in the field. Despite the good intentions of the research team and the teachers, in order to determine better results, teachers would have needed a longer exposure to media and intercultural education practices to shape, model and improve their teaching activities. This is consistent with other studies highlighting how ephemeral interventions risk being less effective (Trültzsch-Wijnen, 2014). However, where teachers were more used to collaborating in the classroom, the impact of time limitations was more attenuated. 
This was the case of Italy where teachers were more familiar with cross-curricular approaches when compared to the Slovenian context.

Time constraints also had a negative impact on teachers' capacity to learn how to deal with critical situations. This is not surprising. Managing media education projects entails teachers' monitoring and control of several factors ranging from the use of technologies to the approach of sensitive topics (e.g. racism, gender issues, hate speech, social justice), which may lead to controversial discussions, if not conflicts among participants. In all countries participating in the project, a longer programme would have allowed teachers to become more confident towards the several challenges that these complex situations may raise. This was particularly clear with those activities specifically focused on intercultural issues such as, for example, media representations of migrants and migration. A lack of familiarity with students' backgrounds as well as a lack of training on intercultural communication brought sometimes teachers to approach certain topics in moralistic terms. However, political correctness is not enough to solicit deep learning about the media on the part of the students (Ranieri, Fabbro \& Frelih, 2016).

Despite these limitations, teachers' involvement in the MEET action-research project also generated benefits for their professional growth. They had access to new pedagogical strategies while increasing their awareness about the potential of multimedia tools for teaching. In particular, they learned new techniques such as media analysis and production. In this regard, it must be underlined the positive influence that the exposure to experts' practices had on their understanding of teaching about the media. Modelling and co-teaching proved to be a suitable strategy to promote knowledge around new instructional practices. This was particularly true in Slovenia, where the introduction of media and intercultural education is fairly recent.

Even the participation in the co-design of MEET learning scenarios was relevant to develop new competences since it offered teachers the opportunity to reflect on the nature of media literacy, which must not be confused with more instrumental approaches to media and technology in education, as well as to the strategies that can be used to facilitate students' understanding, expression and engagement (Ranieri \& Fabbro, 2018). From this point of view, the engagement in the action-research project allowed teachers to increase their understanding of students' cultural background and improve their capacity to build and encourage intercultural dialogues. Indeed, since students developed higher level of self-expression, teachers could go deeper into the relationship with the students and know more of their backgrounds and better.

Finally, it should be observed that the positive implications generated by the implementation of the media and intercultural education activities seem to run in two directions, that is not only from the teacher to the student - the teachers' improved intercultural awareness produced a better climate and facilitated intercultural dialogue in the classroom - but also from the student to the teacher. Specifically, in this virtuous circle from the teachers to the students and vice versa, the students, especially those with migrant backgrounds, could become, by sharing their experiences, their reflections and their attitude, bearers of intercultural values for the whole class, including teachers. As such, it is the students themselves who enrich the intercultural awareness of their teachers: in the best cases, the latter are induced to revise their own "feel-good" and moralistic views or more simply to reach a deeper understanding of the issues at stake through the direct contribution of their students. In Germany, where political and civic education has a longer tradition within the school, a more suitable background to dealing with social and political issues was found, which enabled positive interactions among students, teachers and educators.

\section{Conclusions and recommendations}

Although this study brought us to a better understanding of the impact of action-research projects on teachers' capacity to teach media literacy in intercultural classes, it has some limitations that prevent the generalisation of its results. In fact, the general sample was very small and there were differences between the different national contexts. As a strategy to control these limitations, repeated sessions of member checking were carried out either with teachers who were involved in the evaluation process or with researchers who directly took part in the action-research project at a national level and/or wrote the national report.

Looking at future developments through the lens of the constraints and the affordances discussed in this article, certain conditions seem to be of fundamental importance to better support teachers' improvement in CMIE:

- Increased support should be provided to the school and the teachers for the complex management of media production activities on intercultural issues (i.e. migration, discrimination, etc.) through, for example, the establishment of long-lasting Media Literacy Education Programme at school and the funding of dedicated workshops for teachers led by media educators along with media professionals (i.e. journalists, video makers, etc.).

- Increased "action-oriented" training activities addressing teachers on media and intercultural education should be planned: for example, teachers should be encouraged to be actively involved into EIs co-designed with media education experts and other relevant stakeholders (i.e. NGOs, CVOs, etc.) in the field of human rights, antidiscrimination, etc.

- Increased involvement of school leaders in teacher-training-related issues and in the organisation of the curriculum should be invigorated through specific actions aimed at raising their awareness of these topics, including actionresearch experiences and wider initiatives of professional development. 
- "Bottom-up" strategies in the design of media and intercultural education interventions in the school should be promoted, specifically through initiatives aimed at involving students in the design process by taking into account their media and (inter-) cultural habits and practices.

- The development of a curriculum at the national level on media and intercultural education should be supported through the building up of a national panel of experts in charge of defining specific key competences, contents and paedagogical strategies.

\section{Acknowledgement}

This study was carried out within the framework of the European-funded project MEET (Erasmus Plus Programme, KA3, 2016-19, EC Project Number: 580286-EPP-1-2016-1-IT-EPPKA3-IPI-SOC-IN). All contents of this article are the sole responsibility of the University of Florence (Italy) and can in no way be taken to reflect the views of the European Commission.

\section{References}

Bezjak, S., \& Klemenčič, E. (2014). Learning active citizenship through volunteering in compulsory basic education in Slovenia. Traditiones, 43(3), 51-65.

Braun, V., \& Clarke, V. (2006). Using thematic analysis in psychology. Qualitative Research in Psychology, 3(2), 77101.

Buckingham, D. (2003). Media education. Literacy, learning and contemporary culture. London: Polity PressBlackwell Publishing.

European Parliament and the Council of the European Union (2006). Recommendations of the European Parliament and of the Council of 18 December 2006 on Key Competences for Lifelong Learning (2006/962/EC) (Official Journal of the European Union. 30.12.2006).

Hill, I. (2006). Student types, school types and their combined influence on the development of intercultural understanding. Journal of Research in International Education, 5(1), 5-33.

Hobbs, R. (2010). Digital and Media Literacy: A Plan of Action. Knight Commission on the Information Needs of Communities in a Democracy. Aspen Institute: Washington DC.

Kavanagh, J., Campbell, F., Harden, A., \& Thomas, J. (2012). Mixed methods synthesis: a worked example. In K. Hannes, \& C. Lockwood (eds.), Synthetizing Qualitative Research: Choosing the Right Approach (pp. 113-136). Chichester, UK: John Wiley \& Sons, Ltd.

Mayer, K. (2018). National report on the testing phase in Germany. MEET Project. Deliverable 4.5. Ludwigshafen am Rhein: medienbildung.com.

Meyer, A., Rose, D. H., \& Gordon, D. (2014). Universal Design for Learning: Theory and Practice. Wakefield, MA: CAST Professional Publishing.

Noblit, G. W., \& Hare, R. D. (1988). Meta-ethnography: Synthesizing qualitative studies. Newbury Park, CA: Sage.

Opratko, B., \& Sauer, B. (2019). Citizenship, media literacy and intercultural education. Reflections and recommendations for policy transformation. In M. Ranieri (ed.), Media education for equity and tolerance. Theory, policy and practices. Roma: Aracne.

Parola, A., \& Ranieri, M. (2010). Media education in action. A research study from six European countries. Firenze: FUP.

Perry, L. B., \& Southwell, S. (2011). Developing intercultural understanding and skills: models and approaches. Intercultural Education, 22(6), 453-466.

Ranieri, M., \& Bruni, I. (2018). Digital and media literacy in Teacher Education: Preparing undergraduate teachers through an academic program on digital storytelling. In J. Cubbage (ed.), Handbook of Research on Media Literacy in Higher Education Environments (pp. 90-111), Hershey, PA: IGI Global.

Ranieri, M., \& Fabbro, F. (2018). Designing media literacy education for intercultural contexts. The MIEF framework and guidelines (pp. 6002-6008). In INTED2018, Valencia, Spain, 5th-7th March, 2018, IATED Academy.

Ranieri, M., Fabbro, F., \& Frelih, M. (2016). Making sense of students' media literacy and civic agency across media analysis and production. In Ranieri M. (ed.), Populism, Media and Education. Challenging Discrimination in Contemporary Digital Societies (pp. 127-146). Abingdon, New York: Routledge.

Ranieri, M., Fabbro, F., \& Nardi, A. (2018). National report on the testing phase in Italy. MEET Project. Deliverable 4.5. Florence: University of Florence.

Ranieri, R., Fabbro, F., \& Nardi, A. (2018). Media education in intercultural contexts: an action research for social change. Synthesis Report of the Testing Phase. MEET Project, Work Package 4 - Deliverable 4.6. Florence: University of Florence.

Ranieri, M., \& Fabbro, F. (2019). Theorising and designing media and intercultural education: A Framework and Some Guidelines. In M. Ranieri (ed.), Media education for equity and tolerance. Theory, policy and practices. Roma: Aracne.

Šori, I., \& Frelih, M. (2018). National report on the testing phase Slovenia. MEET Project. Deliverable 4.5. Ljubljana: Peace Institute. 
Šori, L., \& Pajnik, M. (2019). Policies on Citizenship, Media and Intercultural Education: A Comparative Perspective of European states. In M. Ranieri (ed.), Media education for equity and tolerance. Theory, policy and practices. Roma: Aracne.

Strauss, A. L., \& Corbin, J. (1998). Basics of Qualitative Research: Techniques and Procedures for Developing Grounded Theory. Thousand Oaks, CA: Sage.

Thomas, J., \& Harden, A. (2008). Methods for the thematic synthesis of qualitative research in systematic reviews. BMC Medical Research Methodology, 8(45), 1-10.

Trültzsch-Wijnen, C. W. (2014). Media and information Literacy Policies in Austria (2013). Salzburg, ANR TRANSLIT and COST "Transforming Audiences/Transforming Societies". Retrieved from http://ppemi.enscachan.fr/data/media/colloque140528/rapports/AUSTRIA_2014.pdf

Wetterich, F., Burghart, M., \& Rave, N. (2014). Medienbildung an deutschen Schulen. Handlungsempfehlungen für die digitale Gesellschaft. Initiative D21 (Schirmherr). Berlin: Atene KOM. Retrieved from https://initiatived21.de/app/uploads/2017/01/141106_medienbildung_onlinefassung_komprimiert.pdf. 